\title{
Design and analysis of the movable solar energy heat utilization system
}

\author{
Zijian Chen ${ }^{1}$, Lian Zhang ${ }^{1,2, a}$ and Jinlin Zhang ${ }^{1}$ \\ ${ }^{1}$ School of electrical and energy, Tianjin Sino-German University of AppliedSciences, Tianjin, China \\ http://www.zdtj.cn/ \\ ${ }^{2}$ China Computer-Room Equipment Engineering CO.,LTD, Tianjin, China
}

\begin{abstract}
This paper describes the design of the movable solar energy heat utilization system. The data of the system can be monitored and output for testing and analysis. The system can save $3386.4 \mathrm{kWh}$ of electricity per year.It can be known that this system uses only two hours to heat water for daily life.The system equipped batteries can be widely used even without the electric source.
\end{abstract}

Keywords: movable; system design; solar energy heat utilization

\section{Introduction}

The technology of solar thermal utilization is early invented[1], and has been greatly developed and popularized in the world. In recent years, the research of solar thermal utilization is focused on the heat collector[2], system design[3-4] and so on. Considering these questions, this paper design the movable solar energy heat utilization system, the specific contents are as follows.

\section{System design}

The design of the movable solar heat utilization system includes the appearance structure, the heat circulating and the electrical controlling.

\subsection{Appearance structure}

The components of the appearance structure of the system arebased on figure 1 and table 1.The solar flat plate heat collector is mounted on the movable frame. The water tank is fixed in the movable frame. The rolling wheels are installed at the bottom of the movable frame. When the solar flat plate heat collector works, rays of the sunirradiating on the endothermic base,be absorbed and transformed into thermal energy of the water.In the actual environment, the simulated light source can be removed.This system has the ability of movingby rolling wheels, which greatly improves the environmental adaptability.

${ }^{a}$ Corresponding author : $492680311 @$ qq.com

C 2016. The authors - Published by Atlantis Press 

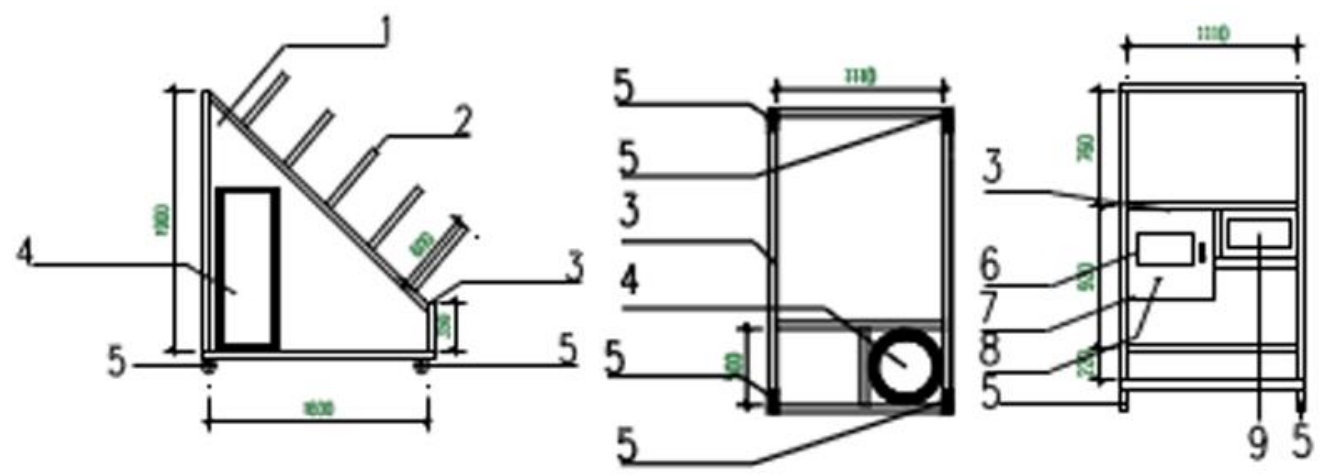

Figure 1. The side view, bottom view andpositive view of the appearancestructure

Table 1. The visible components of the appearance structureaccording to the figure 1

\begin{tabular}{cccc}
\hline $\begin{array}{c}\text { Labels according } \\
\text { to the figure 1 }\end{array}$ & Components & $\begin{array}{c}\text { Labels according to } \\
\text { the figure 1 }\end{array}$ & Components \\
\hline 1 & $\begin{array}{c}\text { Solar flat plate heat } \\
\text { collector }\end{array}$ & 6 & $\begin{array}{c}\text { Touch } \\
\text { screen }\end{array}$ \\
2 & Simulated light source & 7 & $\begin{array}{c}\text { Control } \\
\text { cabinet }\end{array}$ \\
3 & Movable frame & 8 & On-off \\
4 & Water tank & 9 & Switch box, \\
5 & Rolling wheels & & \\
\hline
\end{tabular}

\subsection{Heat circulating}

According to figure 2, we can clearly see that the heat circulating of the system belongs to the forced circulation[5]. The DC water pump drives water between the water tank and the solar flat plate heat collector[6]. The use of the electromagnetic valve is to injectcold water to the water tank when the water volume is insufficient. The ultrasonic heatmeter[7]measures the flow rate and the temperature of the waterviatwo different sensors, and then calculates the thermal energyby a series of integral calculation. The liquid level sensorconverted the static pressureinto standard electric signal.Driven by the pumpto the collector,the cold water flowedout of the water tank.After absorbing the thermal energy of light, itis converted into hot waterand returnedto the water tank. This process forms a cycle that will achieve the purpose of heating the water continuously. The water from external water sourcecan is injected into the water tankthrough the inlet in the case of open the electromagnetic valve. The hot water can be used when opening the manual valve. Theelectric auxiliary heater can heat water in the absence of light. The data from the heat meter and the liquid level sensor are transmitted to the I/O controlboardfor controlling the pump, the electromagnetic valve and the electric auxiliary heater.Detailed design refers to figure 2 and table 2. 


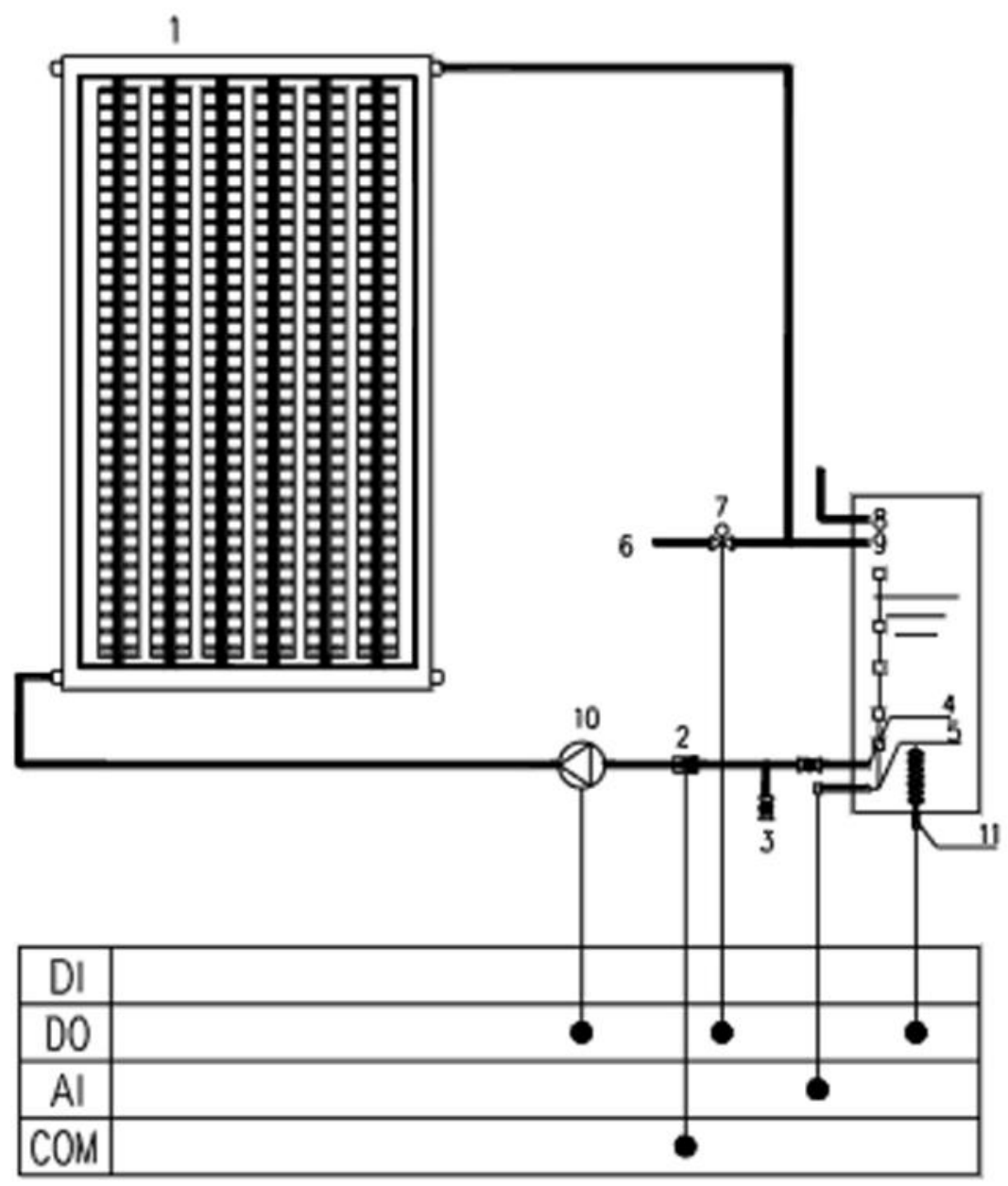

Figure 2. The schematic of the heat circulating

Table 2. The components of the heat circulating according to the figure 2

\begin{tabular}{|c|c|c|c|}
\hline $\begin{array}{l}\text { Labels according to } \\
\text { the figure } 2\end{array}$ & Components & $\begin{array}{l}\text { Labels } \\
\text { according to } \\
\text { the figure } 2\end{array}$ & Components \\
\hline 1 & $\begin{array}{l}\text { Solar flat plate heat } \\
\text { collector }\end{array}$ & 7 & $\begin{array}{l}\text { Electromagnetic } \\
\text { valve }\end{array}$ \\
\hline 2 & Ultrasonic heat meter & 8 & Exhaust port \\
\hline 3 & Drainage terminal & 9 & Water inlet \\
\hline 4 & Water outlet & 10 & DC water pump \\
\hline 5 & Liquid level sensor & 11 & $\begin{array}{c}\text { Electric auxiliary } \\
\text { heater }\end{array}$ \\
\hline 6 & External water source & & \\
\hline
\end{tabular}

\subsection{Electrical controlling}

AC220V is converted into DC $24 \mathrm{~V}$ by rectifier and transformer. The AC contactorcontrolsthe heater, and two electric relays controlthe pump and the electromagnetic valve respectively. Since M-Bus of the ultrasonic heat meter is not coupled with RS485 protocol of theI/O control board, the conversion 
moduleneed toconvertthe data[8]. The I/O control boardincludes CPU, ports, interface,communication chips, and all kinds of conversion chips.

In the electrical controlling circuit, $220 \mathrm{~V}$ ACcan be suppliedforlight source, the contactor and the heater.It also can be converted to $24 \mathrm{~V} \mathrm{DC}$, whichcan be supplied for the pump, the electromagnetic valve, the relays, the heat meter, the conversion module, the liquid level sensor, the touch screen and I/Oboard. The data of the conversion module and the data of the touch screen are communicated to the $\mathrm{COM}$ interface of the I/O board. The liquid level sensor data are input to the analog input (AI) port of the I/O board, and then the I/O board outputs the signal through the digital output (DO) ports tothe contactor and the relays. The I/O board can automatically control the relevant output signals according to the obtained data. Above working principle are basedon figure 3 and table 3 . It is worth mentioning that thelight source and the heater depend on the $220 \mathrm{~V}$ AC power supply, but the other components of the electrical controllingonly depend on the $24 \mathrm{~V}$ DC power supply. So the system equipped batteries can be widely used even without the electric source.

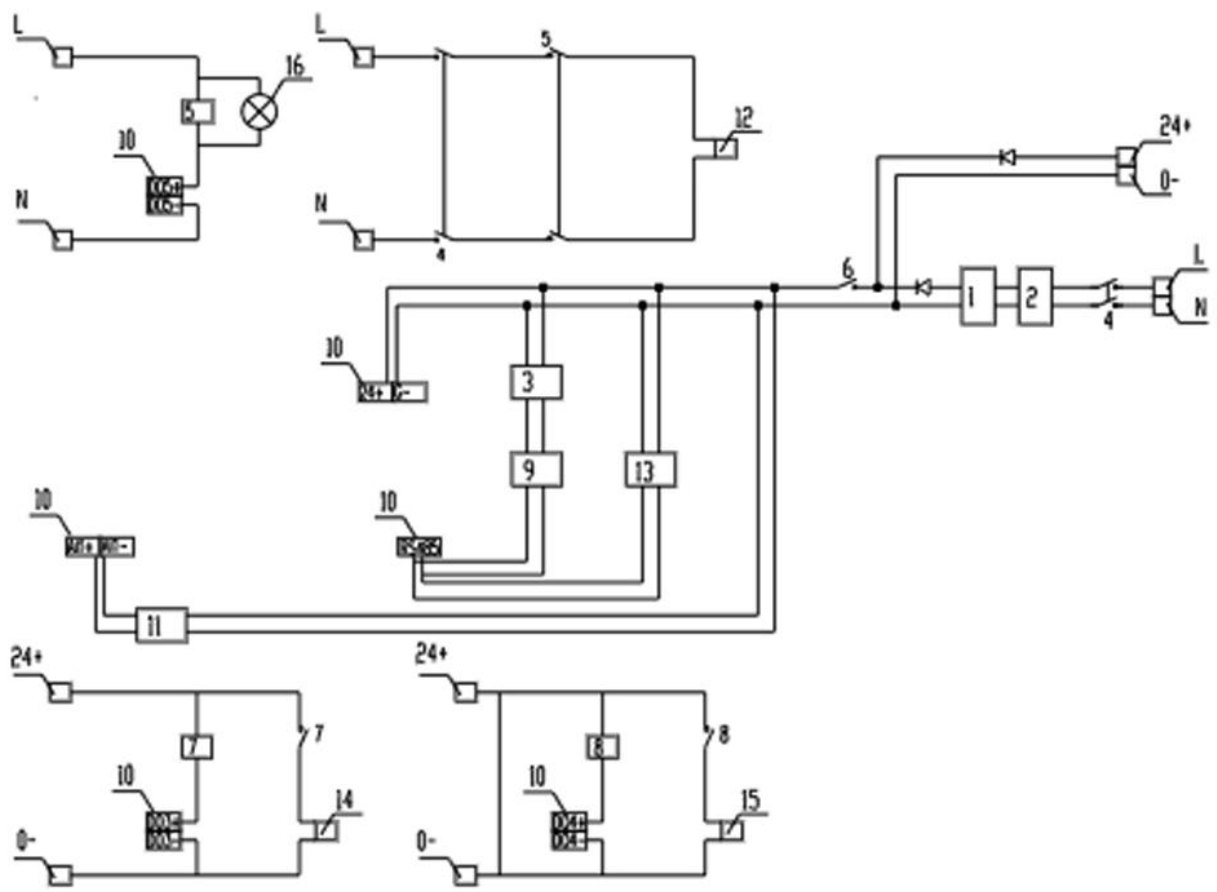

Figure 3. The electrical schematic of the system

Table 3. The components of the electrical controlling according to the figure 5

\begin{tabular}{cccc}
\hline $\begin{array}{c}\text { Labels according to } \\
\text { the figure 3 }\end{array}$ & Components & $\begin{array}{c}\text { Labels according to } \\
\text { the figure } 3\end{array}$ & Components \\
\hline 1 & Rectifier & 10 & I/O control board \\
2 & Transformer & 11 & $\begin{array}{c}\text { Liquid level sensor } \\
\text { Electric auxiliary } \\
\text { heater }\end{array}$ \\
3 & mettrasonic heat & 12 & Touch screen \\
4 & Air switches & 13 & DC water pump \\
5 & AC contactor & 14 & Electromagnetic \\
6 & On-off & 15 & valve \\
7 & & & Pilot lamp \\
8 & Electric relays & 16 & $220 \mathrm{~V}$ AC \\
9 & Conversion & L,N & $24 \mathrm{~V}$ DC \\
& module & & \\
\hline
\end{tabular}




\section{System testing and analysis}

The monitoring and controlling of the system relieson thetouchscreen. Users can monitor the automatic state, and also can control the manualstate.Meanwhile the real-time data and historical data such as temperature, thermal energy, rate of flow and power of the system can be collected and downloaded. Figure 4 is the experimentaldatacollected by the touch screen. The temperature and thermal energyof the system can be acquired in working condition.It can be known that this system uses only two hours to heat water for daily life.

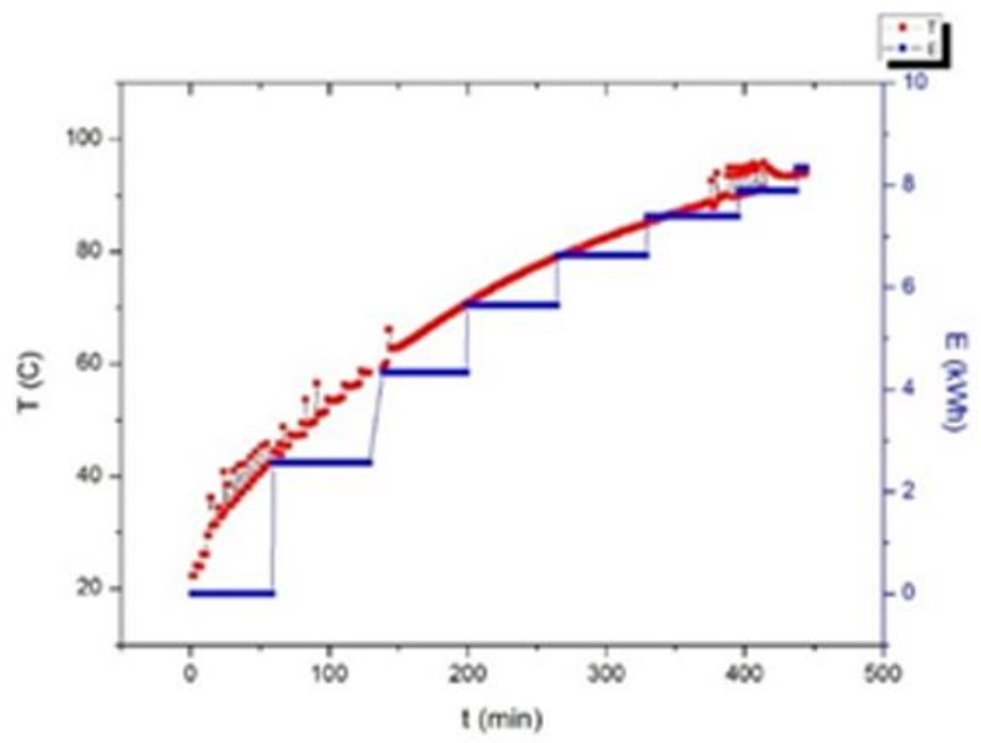

Figure 4.Temperature and thermal energy of the system in working condition.

The thermalenergy of the system is about $8.35 \mathrm{kWhaccording}$ the data. The energy saving can be calculatedaccording to Eq. (1):

$$
\Delta Q=\frac{E}{\eta}
$$

Where:

$\mathrm{E}=$ Theenergy of each heat utilization system, $\mathrm{kWh}$;

$\Delta \mathrm{Q}=$ The energy saving of the system, $\mathrm{kWh}$;

$\eta=$ The efficiency of the electric water heater, $\%$;

Taking into account $\eta$ is roughly90\%, the energy savingis $9.28 \mathrm{kWh}$. The system can save 3386.4 kWh of electricity per year.

\section{Conclusion}

The main features of this system are as follows.

(i)The system can be used for the outdoor application of daily life in backward areas or lonely islands and the indoor teaching and training of energy specialty.

(ii)The system has the function of data collectionandenergyconsumptionanalysis. The system can save $3386.4 \mathrm{kWh}$ of electricity per year.It can be known that this system uses only two hours to heat water for daily life.

(iii)The system equipped batteries can be widely used even without the electric source. 


\section{Acknowledgments}

This work was supported by the Science Fund of Tianjin Urban and Rural Construction Commission (Grant No. 2014-34) and Tianjin Higher Education Science and Technology Fund Planning Project (Project No. 20140426).

\section{References}

1. D.W. Coxon and T.P. Gates, Solar heat air system, U. S. Pantent,4,203,424, 1980-5-20

2. J.F.Lu and J.Ding, Heat transfer performance and exergetic optimization for solar receiver pipe, Renewable Energy, 1477-1483,35(2010)

3. L.Zhang andY.F.Zhang, Research on Energy Saving Potential for Dedicated Ventilation Systems Based on Heat Recovery Technology. Energies,4261-4280, 7,(2014)

4. L.Zhang and Y.F.Zhang, Research on Heat Recovery Technology for Reducing the Energy Consumption of Dedicated Ventilation Systems: An Application to the Operating Model of a Laboratory, Energies, 24,9,(2016)

5. C.S.Lin and M.L.Lin, Development and applications of a fuzzy controller for a forced circulation solar water heater system, Journal of Scientific \& Industrial Research, Vol. 69, 7,(2010), pp. 537542

6. T. BERGENEandO. M. LOVVIK, Model calculations on a flat-plate solar heat collector with integrated solar cells, Solar Energy, Vol. 55, No. 6,(1995), pp. 453-462

7. W.L.Wang and C.C.Huang, The study of ultrasonic heat meter straight pipe length based on the CFD, 2nd International Conference on Machinery, Materials Engineering, Chemical Engineering and Biotechnology, (2015)

8. L.BaiandM.Liu,Research on the detecting system of distributed nodes based on RS-485 bus, International Conference on Educational \& Network Technology,422 - 425,(2010) 